\title{
Polar cap ionosphere and thermosphere during the solar minimum period: EISCAT Svalbard radar observations and GCM simulations
}

\author{
Hitoshi Fujiwara ${ }^{1,2}$, Satonori Nozawa ${ }^{3}$, Sawako Maeda ${ }^{4}$, Yasunobu Ogawa ${ }^{5}$, Yasunobu Miyoshi ${ }^{6}$, \\ Hidekatsu Jin $^{7}$, Hiroyuki Shinagawa ${ }^{7}$, and Kaori Terada ${ }^{1}$ \\ ${ }^{1}$ Department of Geophysics, Tohoku University, Sendai, Japan \\ ${ }^{2}$ Faculty of Science and Technology, Seikei University, Japan \\ ${ }^{3}$ Solar Terrestrial Environment Laboratory, Nagoya University, Nagoya, Japan \\ ${ }^{4}$ Kyoto Women's University, Kyoto, Japan \\ ${ }^{5}$ National Institute of Polar Research, Tokyo, Japan \\ ${ }^{6}$ Department of Earth and Planetary Sciences, Kyushu University, Fukuoka, Japan \\ ${ }^{7}$ National Institute of Communication Technology, Tokyo, Japan
}

(Received June 2, 2010; Revised February 14, 2011; Accepted May 6, 2011; Online published July 27, 2012)

The IPY long-run data were obtained from the European Incoherent Scatter Svalbard radar (ESR) observations during March 2007 and February 2008. Since the solar and geomagnetic activities were quite low during the period, this data set is extremely helpful for describing the basic states (ground states) of the thermosphere and ionosphere in the polar cap region. The monthly-averaged ion temperatures for 12 months show similar local time (or UT) variations to each other. The ion temperatures also show significant seasonal variations. The amplitudes of the local time and seasonal variations observed are much larger than the ones predicted by the IRI-2007 model. In addition, we performed numerical simulations with a general circulation model (GCM), which covers all the atmospheric regions, to investigate variations of the neutrals in the polar thermosphere. The GCM simulations show significant variations of the neutral temperature in the polar region in comparison with the NRLMSISE-00 empirical model. These results indicate that both the ions and neutrals would show larger variations than those described by the empirical models, suggesting significant heat sources in the polar cap region even under solar minimum and geomagnetically quiet conditions.

Key words: Polar cap, ionosphere, thermosphere, EISCAT radar, GCM, simulation, IPY, solar minimum.

\section{Introduction}

During the last decade, the variations, dynamical features, temperature and density structures in the polar cap and/or cusp region of the thermosphere/ionosphere have been clarified from radar and satellite observations (e.g., Innis and Conde, 2001; Maeda et al., 2002; Lühr et al., 2004; Liu et al., 2005; Fujiwara et al., 2007; Clemmons et al., 2008; Maeda et al., 2009, and references therein). In addition to recent works, Moe and Moe (2008) have reviewed historical studies on the high-latitude thermospheric mass density anomaly. Some studies have pointed out that there would be significant thermospheric/ionospheric variations in the polar cap and/or cusp region, although significant energy sources were thought to be located in the region near the auroral oval.

Innis and Conde (2001) showed activities of small-scale gravity waves in the polar cap region at about $300-\mathrm{km}$ altitude from a statistical analysis of the Dynamics Explorer 2 (DE 2) satellite data; the polar cap was filled with fluctuations due to gravity waves, although fluctuations were very few outside the polar cap. The Challenging Minisatel-

Copyright (C) The Society of Geomagnetism and Earth, Planetary and Space Sciences (SGEPSS); The Seismological Society of Japan; The Volcanological Society of Japan; The Geodetic Society of Japan; The Japanese Society for Planetary Sciences; TERRAPUB.

doi: $10.5047 /$ eps.2011.05.023 lite Payload (CHAMP) satellite has observed thermospheric mass density. Lühr et al. (2004) found density enhancements of almost a factor of two at about $450-\mathrm{km}$ altitude when the satellite passed the cusp region, suggesting atmospheric up-welling caused by local Joule heating in the cusp region. Liu et al. (2005) showed a large discrepancy between the CHAMP observations and the MSISE-90 empirical model (Hedin, 1991) in the cusp region at $400-\mathrm{km}$ altitude.

Studies on temperature and energetics in the polar cap and/or cusp region of the thermosphere/ionosphere, particularly at the $F$ region height, are very few. One important result was presented by Killeen et al. (1995). They showed thermospheric temperature variations at the $F$ region height in the winter polar cap region during the solar minimum and maximum periods from Fabry-Perot interferometer measurements. Maeda et al. (2002, 2009) showed ion temperature variations in the polar cap/cusp region from the European incoherent scatter (EISCAT) Svalbard radar (ESR) observations. Maeda et al. (2009) found high-temperature regions in the flow channel of the polar cap ion-convection due to frictional heating near the fast ion flow channel. From simultaneous observations with the ESR and CUTLASS Finland radar, Fujiwara et al. (2007) also obtained a significant thermospheric heating rate in the cusp/polar cap region of the upper thermosphere when 
pulsed ionospheric flows were observed.

Some interesting features of the thermosphere/ionosphere in the polar cap/cusp region have been found as above. However, energy and momentum budgets, or generation mechanisms of disturbances in the polar cap/cusp region, are still unknown because of a lack of comprehensive observations in the region. The ESR has provided valuable data of the ionospheric parameters in the polar cap/cusp region. In particular, the ESR observations during the period of International Polar Year (IPY) enable us to understand the ionosphere in the polar cap/cusp region during the solar minimum and geomagnetically quiet conditions which would produce the basic state of the polar cap ionosphere. In the present study, we show diurnal and seasonal variations of the ion temperature at about $300-\mathrm{km}$ altitude obtained from the ESR observations in the IPY period during March 2007 and February 2008. We also show the neutral temperature variations simulated by a general circulation model (GCM) to discuss the relation between the ion and neutral temperatures in the polar cap region.

\section{ESR Observations during the IPY Period}

The ESR, which is located on $78.09^{\circ} \mathrm{N}, 16.03^{\circ} \mathrm{E}$ $\left(75.12^{\circ} \mathrm{N}, 113.00^{\circ} \mathrm{E}\right.$ in geomagnetic coordinates), can observe the polar cap/cusp ionosphere from the $E$ to $F$ regions. During the IPY period between March 1, 2007, and February 29, 2008, the ESR provided continuous data of the ionospheric parameters. Since the solar and geomagnetic activities were quite low during this period, this data set is extremely helpful for describing the basic states (ground states) of the thermosphere and ionosphere in the polar cap region. The observing modes include field-aligned profiles from about 100- to 500-km altitude (with the ESR 42-m antenna) and 30+ hour local area scans (for electric field measurements) every two weeks. In the present study, we show the ion temperature data obtained in the field-aligned direction at about 300-km altitude every 2 minutes. Detailed information of the EISCAT IPY continuous run is described at the web page http://www.eiscat.se/groups/IPY/.

\section{GCM Simulations}

In the present study, we also show simulation results by a general circulation model (GCM) which was developed by Miyoshi and Fujiwara (2003) as an extension of the middle atmosphere GCM at Kyushu University (Miyahara et al., 1993; Miyoshi, 1999). The GCM was originally developed as a tropospheric GCM at the Japan Meteorological Agency (Kanamitsu et al., 1983), and developed as a community climate model at the University of Tokyo. The GCM was extended to include the processes of the middle atmosphere, and then the thermosphere. The details of the GCM have been described in previous works (e.g., Miyoshi and Fujiwara, 2003, 2006, 2008; Fujiwara and Miyoshi, 2006, 2010 and references therein).

In order to describe the thermospheric neutral temperature during the solar minimum and geomagnetically quiet periods, we assume that the cross polar cap potential drop is $30 \mathrm{kV}$ and the $F_{10.7}$ index is $70 \times 10^{-22} \mathrm{~W} / \mathrm{m}^{2} / \mathrm{Hz}$. Some of the GCM results obtained under the same conditions have been already shown in Fujiwara and Miyoshi (2010).

\section{Results}

First, we show the monthly-averaged values of the $F_{10.7}$ and $A_{\mathrm{p}}$ indices from January 2000 to December 2009 in Fig. 1. The vertical dashed lines indicate the period of the IPY observations. Figure 1 shows that the solar radiative flux and geomagnetic activity were quite low during March 2007 and February 2008; the averages of the $F_{10.7}$ and $A_{\mathrm{p}}$ indices during this period are 71.8 and 8 , respectively.

The ion temperature in the field-aligned direction at about $300-\mathrm{km}$ altitude is obtained every 2 minutes from the ESR observations. Figure 2 shows examples of the diurnal variations of the ion temperature: the ion temperatures at about 300-km altitude on March 18 and 25, 2007. Although the ESR observations during the IPY period sometimes have data losses, these examples on March 18 and 25 are almost complete data, having only a few data losses during a day. The ion temperature variations in Fig. 2 show spiky excursions due to enhancements of the geomagnetic activity, particularly in the case of March 25. In addition, fluctuations with periods from several tens of minutes to 1-2 hours are seen, particularly in the case of March 18. The amplitudes of the fluctuations seem to be several tens to about $100 \mathrm{~K}$.

The ion temperature data at about $300-\mathrm{km}$ altitude obtained in the field-aligned direction with the IPY observational mode are divided into 24 UT bins for each month and are averaged; for example, the value plotted at 01:00 UT in Fig. 3 denotes the average of data obtained during 00:3001:30 UT. The numbers of the ion temperature data used for the above statistical analysis are 15738 in March 2007, 17443 in April 2007, 14401 in May 2007, 15907 in June 2007, 16939 in July 2007, 12893 in August 2007, 13236 in September, 14306 in October, 3416 in November 2007, 6514 in December 2007, 5436 in January 2008, and 14428 in February 2008. Figure 3 shows UT or local time (the solar local time at the ESR site is UT+1) variations of the averaged ion temperature for 12 months. The numbers labeled in the figure indicate the month. The ion temperatures obtained from the ESR observations show similar UT or local time (LT) variations in all the months. The amplitudes of the diurnal variations are about $200 \mathrm{~K}$ or more. The high temperatures appear at 03:00-05:00 UT (04:0006:00 LT) and 11:00-13:00 UT (12:00-14:00 LT). The maximum range of the seasonal variation is about $350 \mathrm{~K}$ at around 02:00 UT.

Figure 4 is the same as Fig. 3, except for the ion temperature obtained from the International Reference Ionosphere (IRI) 2007 model (Bilitza and Reinisch, 2008). The ion temperature in each month is shown in the same color as in Fig. 3. The amplitudes of the diurnal variations $(\sim 20 \mathrm{~K})$ and seasonal variations $(\sim 100 \mathrm{~K})$ are much smaller than those seen in the ESR observations. In addition, the highest temperature is seen in June in the IRI-2007 model results, while the ESR observations show the highest temperature in March. The pattern of the diurnal variation of the IRI-2007 model temperature is also different from that of the ESR observations; the IRI-2007 model shows the maximum temperature at around 18:00 UT, while the ESR observations show the maximum temperature at around 03:00-04:00 or 

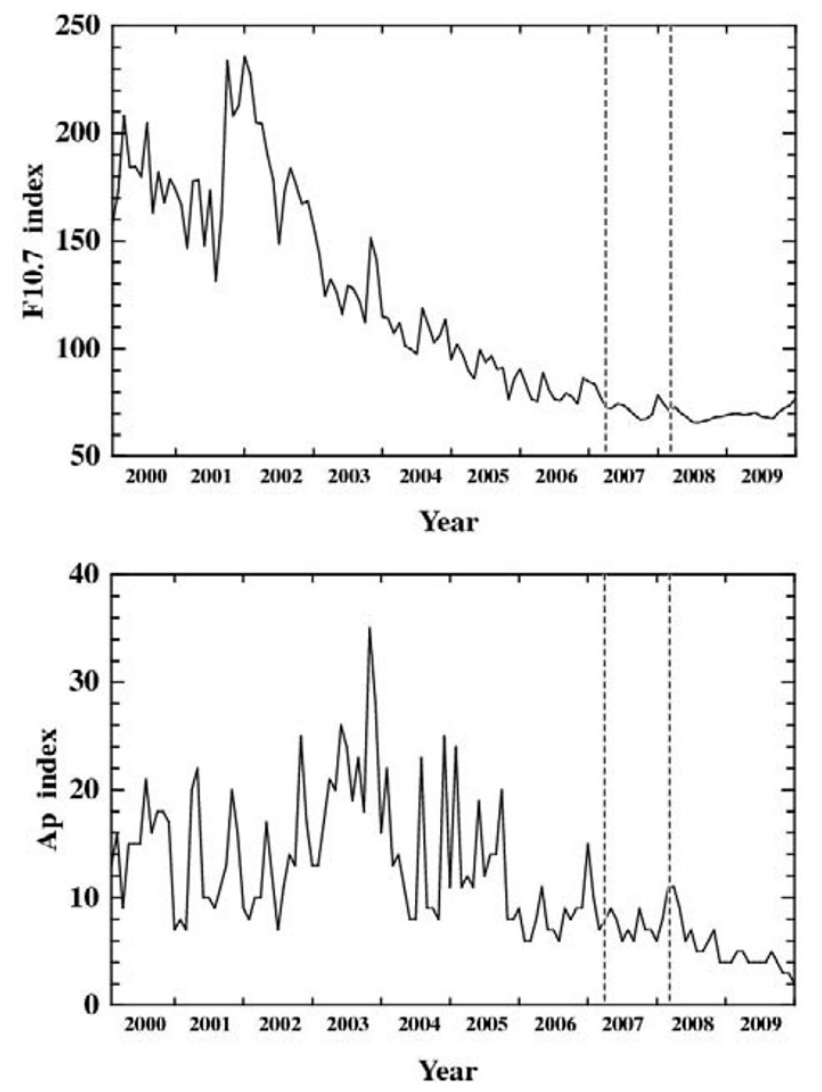

Fig. 1. Monthly-averaged values of the $F_{10.7}$ (upper panel) and $A_{\mathrm{p}}$ (bottom panel) indices from January 2000 to December 2009. The vertical dashed lines indicate the IPY period of the ESR observations.

\section{1:00-12:00 UT.}

Figure 5 shows the averaged ion temperature obtained from the ESR observations and the ion temperature from the IRI-2007 model in March. The error bars of the ESR ion temperature denote the standard errors of the mean. The IRI temperature is within the range of the ESR temperature variations although the ESR temperature has large amplitudes as mentioned above; the ion temperatures from the ESR observations are about $120 \mathrm{~K}$ larger or smaller than those from IRI-2007 in this case. In addition to the ion temperature, the neutral temperature obtained from an empirical model of NRLMSISE-00 (Picone et al., 2002) is also shown. The ion temperature from IRI-2007 is larger than the neutral temperature from NRLMSISE-00 by about $250 \mathrm{~K}$.

The neutral temperature at about $300-\mathrm{km}$ altitude in March simulated by the GCM is shown in Fig. 6. The GCM data at about $76^{\circ}$ latitude and $11^{\circ}$ longitude are plotted every 10 minutes. Figure 6 shows a significant day-to-day variation of the neutral temperature with 2-3 hour fluctuations and a seasonal trend. The amplitudes of the neutral temperature variations sometimes exceed $100 \mathrm{~K}$ in the March case. There are large discrepancies between the values of the neutral temperature from the GCM simulations and NRLMSISE-00, probably because of the ambiguity of NRLMSISE-00 in the polar region and simplified (empirical) high-latitude energy inputs in the present GCM simulations.
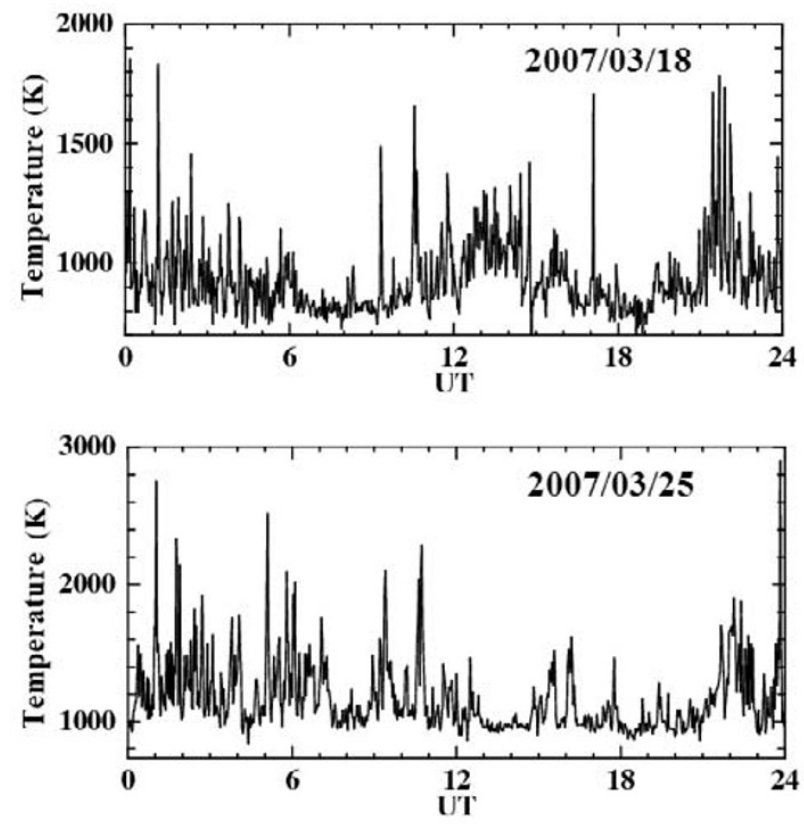

Fig. 2. Examples of the ion temperature variations at about $300-\mathrm{km}$ altitude obtained from the ESR observations. The data of the ion temperature are plotted every 2 minutes. The upper and lower panels show the ion temperature variations on March 18 and 25, respectively.

The neutral temperatures obtained from the GCM simulations are averaged in the same way as the ion temperatures from the ESR observations shown in Fig. 3. The averaged neutral temperatures are plotted in Fig. 7. The amplitude of the diurnal variation shown in Fig. 7 is $59 \mathrm{~K}$, while that of NRLMSISE-00 is $29 \mathrm{~K}$ (see Fig. 5). The maximum temperature is seen at 15:00 UT in Fig. 7, which is similar to NRLMSISE-00 (the maximum temperature of NRLMSISE-00 is at 14:00 UT). The diurnal variation of the GCM temperature shows the second maxima at 01:00 and 22:00 UT, suggesting a relation with the diurnal variation of the ESR ion temperature which also has peaks at 03:0005:00 and 22:00-24:00 UT (Fig. 3) or at around 02:00 and 22:00 UT (upper panel of Fig. 2).

\section{Discussion}

The solar and geomagnetic activities were quite low during the IPY ESR observation period (March 2007-February 2008). Small enhancements of the $A_{\mathrm{p}}$ index in Spring and Fall during the IPY period are seen in the lower panel of Fig. 1. This may be a cause of relatively-high ion temperatures in March and September in 2007, as shown in Fig. 3.

The diurnal variations of the ion temperature obtained from the ESR observations are different from those of IRI2007; high temperatures appear at 03:00-05:00 UT (04:0006:00 LT), 11:00-13:00 UT (12:00-14:00 LT), and 22:0024:00 UT (23:00-01:00 LT) in the ESR ion temperatures. These high temperatures would depend on the relative location of the ESR site to the auroral oval, and/or the cusp region. Maeda et al. (2009) observed the high-speed ion flow channel elongated in 14:00-17:00 MLT (12:30-15:30 LT), suggesting a large frictional heating in the region. This heating may be a heat source for the ions near the ESR 


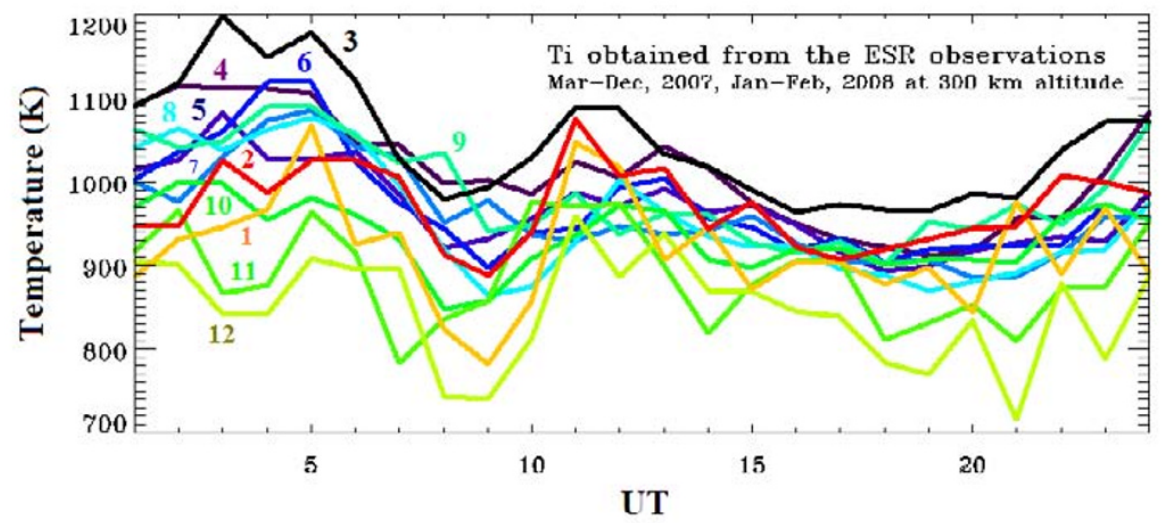

Fig. 3. Monthly-averaged values of the ion temperature obtained from the ESR observations at about $300-\mathrm{km}$ altitude in the field-aligned direction. The numbers labeled in the figure indicate the month.

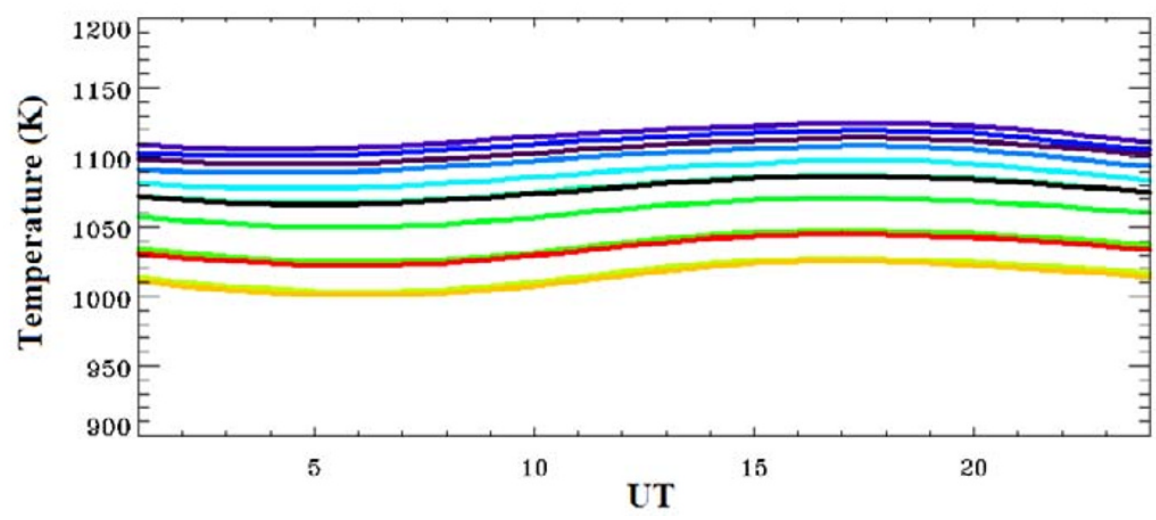

Fig. 4. Same as Fig. 3 except for the ion temperature obtained from the IRI 2007 model. The ion temperature in each month is shown in the same color as in Fig. 3.

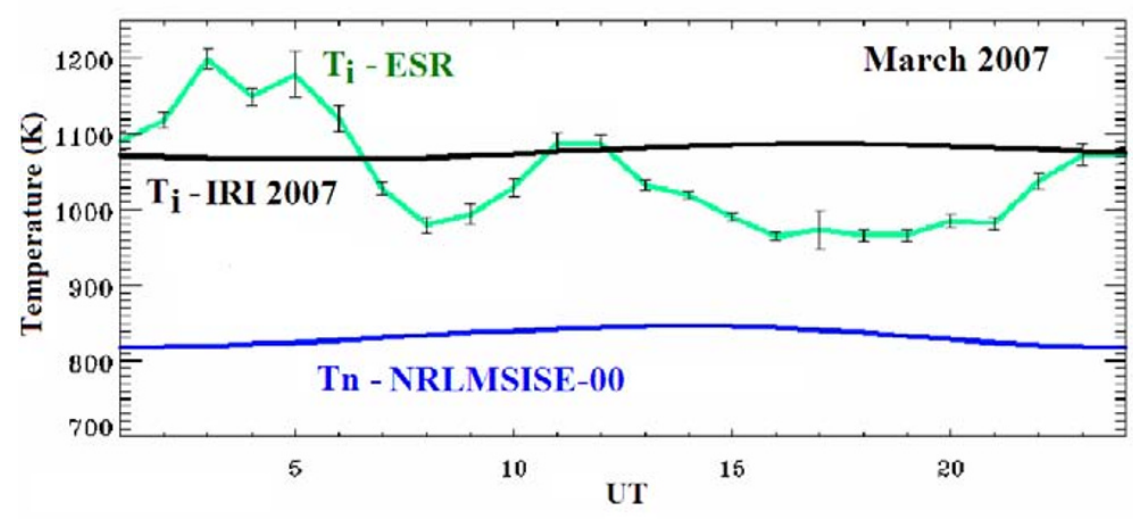

Fig. 5. Monthly-averaged ion temperature obtained from the ESR observations (green line) and the ion temperature from the IRI 2007 model (black line) in March. The error bars of the ESR ion temperature are the standard errors of the mean. In addition to the ion temperature, the neutral temperature obtained from the NRLMSISE-00 model is also shown (blue line).

site even under solar minimum and geomagnetically quiet periods. As shown in Fig. 3, the ion temperature obtained from the ESR observations also show larger amplitudes of diurnal and seasonal variations than those of IRI-2007. The pattern of the diurnal variation of the ion temperature obtained from the ESR observations seems to show a better agreement with that of the neutral temperature simulated by the GCM than that of the ion temperature from IRI-2007 and the neutral temperature from NRLMSISE-00 (see upper panel of Fig. 2 and Fig. 7).

The ion temperature from IRI-2007 is larger than the neutral temperature from NRLMSISE-00 by about $250 \mathrm{~K}$ over the ESR site (see Fig. 5). Since the ion temperatures obtained from the ESR observations vary with large amplitudes, the discrepancy between the ion and neutral temperatures would be larger than $250 \mathrm{~K}$ at a certain moment during 


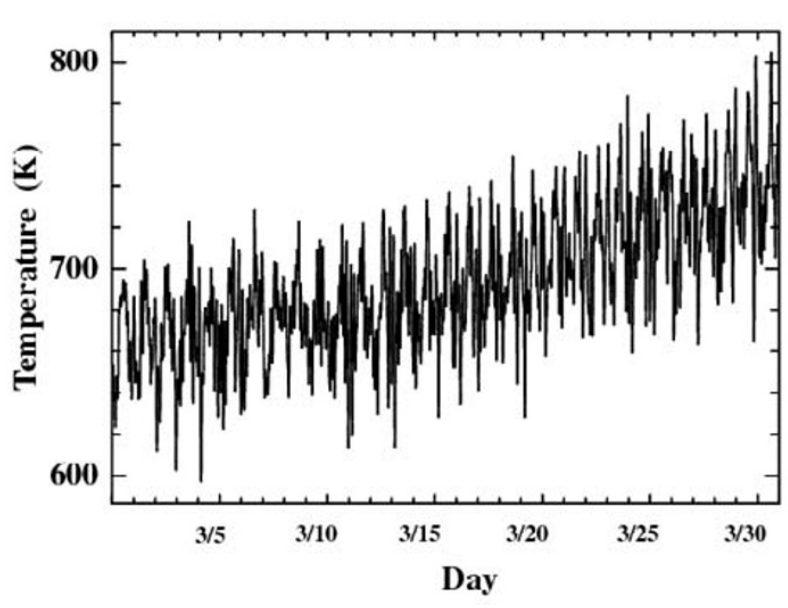

Fig. 6. The neutral temperature at about $300-\mathrm{km}$ altitude at about $76^{\circ}$ latitude and $11^{\circ}$ longitude in March obtained from the GCM simulation. The GCM data are plotted every 10 minutes.

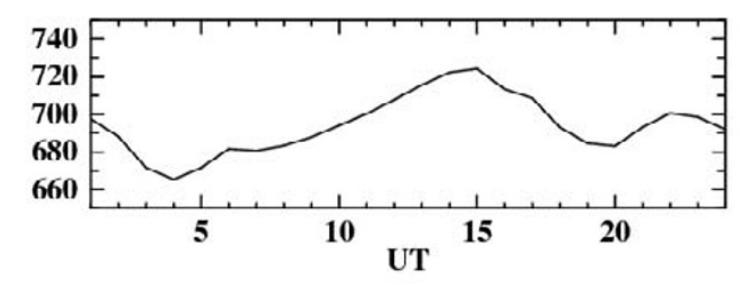

Fig. 7. Monthly-averaged values of the neutral temperature in March obtained from the GCM simulations at about $300-\mathrm{km}$ altitude. The GCM data are averaged in the same way as the ESR ion temperature shown in Fig. 3.

a day. When heat conduction and energy loss to the electrons can be neglected in the steady state, the ion temperature is described as follows (e.g., Schunk and Nagy, 2000),

$$
\begin{aligned}
T_{i} & \approx T_{n}+\frac{m_{n}}{3 k_{B}}\left(\mathbf{V}_{i}-\mathbf{U}_{n}\right)^{2} \\
& =T_{n}+\frac{m_{n}}{3 k_{B}}\left(\frac{\mathbf{E} \times \mathbf{B}}{\mathbf{B}^{2}}-\mathbf{U}_{n}\right)^{2}
\end{aligned}
$$

where $T_{i}$ is the ion temperature (average of perpendicular and parallel components), $T_{n}$ is the neutral temperature, $k_{B}$ is the Boltzmann's constant, $m_{n}$ is the mean mass of the neutral gases, $\mathbf{V}_{i}$ is the ion drift velocity, $\mathbf{U}_{n}$ is the neutral wind velocity, $\mathbf{E}$ is the electric field, and $\mathbf{B}$ is the geomagnetic field. As shown in Eq. (1), the parameters, $T_{i}, T_{n}$, $\mathbf{V}_{i}$ (or $\mathbf{E}$ ), and $\mathbf{U}_{n}$, are related to each other. We should check the consistency between them, both for specific and statistical (empirical) results. If the difference of $250 \mathrm{~K}$ between the ion temperature from IRI-2007 and the neutral temperature from NRLMSISE-00 is correct, a significant electric field would be expected in the polar cap/cusp region even under low solar and geomagnetically quiet periods. From Eq. (1) and $T_{i}-T_{n}=250 \mathrm{~K}$, we can derive $\left|\mathbf{V}_{i}-\mathbf{U}_{n}\right| \sim 589 \mathrm{~m} / \mathrm{s}$. When the neutral wind $\mathbf{U}_{n}$ blows in the same direction as the ion flow, and the strength of the magnetic field is $\sim 48000 \mathrm{nT}$, the amplitude of the electric field is estimated as $|\mathbf{E}| \sim 28,33,38$, and $43 \mathrm{mV} / \mathrm{m}$ for
$\mathbf{U}_{n}=0,100,200$, and $300 \mathrm{~m} / \mathrm{s}$, respectively. This may underestimate the electric field because of the assumption of the wind direction. The lower limit of the magnitude of the electric field is $28 \mathrm{mV} / \mathrm{m}$, although this value is not so realistic. So, we can make a rough estimate of the electric field as $30 \sim$ several $10 \mathrm{mV} / \mathrm{m}$, which would be required to cause the temperature difference $\left(T_{i}-T_{n}\right)$ of $250 \mathrm{~K}$.

In addition to the in-situ forcing/heating in the polar cap/cusp region of the ionosphere and thermosphere, lower atmospheric effects on the temperature and wind variations would be expected (Fujiwara and Miyoshi, 2009, 2010). Fujiwara and Miyoshi (2010) suggested fluctuations in the polar upper thermosphere with periods of 2-3 hours, due to effects from the lower atmosphere. As seen in Fig. 2, the ion temperature variations also include fluctuations with periods from several tens of minutes to 1-2 hours, suggesting lower atmospheric effects. The amplitudes of the ion temperature fluctuations seem to be in agreement with the amplitudes of the neutral temperature fluctuations $(\sim$ several tens of K) simulated by the GCM (Fujiwara and Miyoshi, 2010).

Some researchers have pointed out the importance of the electric field fluctuations for an estimation of the Joule heating rate in the thermosphere (e.g., Codrescu et al., 1995; Matsuo et al., 2003; Matsuo and Richmond, 2008; Deng et al., 2009). Deng et al. (2009) estimated the altitudeintegrated Joule heating, taking into account the electric field variability. They showed large heating rates during about 02:00-13:00 LT at around the $78^{\circ}$ latitude region when the IMF conditions were $B_{y}=0$ and $B_{z}=-5 \mathrm{nT}$, the hemispheric power of precipitating auroral particles was $30 \mathrm{GW}$, and $F_{10.7}$ was $150 \times 10^{-22} \mathrm{~W} / \mathrm{m}^{2} / \mathrm{Hz}$ (figure 1 in their paper). They also pointed out that the horizontal distributions of the altitude-integrated Joule heating and the Poynting flux had some detailed differences in the polar cap and nightside regions, when they considered an electric field variability component consistent with the average electric field. The ion temperature with large peaks during 03:00-05:00 UT, seen in all the months (Fig. 3), may be caused by the above heating effects. The monthly-averaged pattern of the high-latitude electric field (or frictional heating) may be almost independent of season in the polar cap region when the geomagnetic activity is not so variable. In addition, if the solar EUV heating is the dominant heat source, the ion temperature should show a dependence on the solar zenith angle. In the cases of other conditions of solar activity, the local time (or UT) variation may be different for each month; for example, the contributions of solar heating and collisions with neutrals to the energy budget of the polar cap ionosphere may be different from those in the present case. Therefore, the ion temperature variations in the polar cap ionosphere obtained from the IPY data should be important as an experimental proof in the low-solar condition.

As mentioned in the previous section, there are large discrepancies between the neutral temperatures $\left(T_{n}\right)$ obtained from the GCM and NRLMSISE-00 (the GCM temperature is about $100 \mathrm{~K}$ lower than that from NRLMSISE-00), although the pattern of the diurnal variation of $T_{n}$, derived from the GCM simulations, seems to be more consistent 
with that of the ion temperature $\left(T_{i}\right)$ obtained from the ESR observations than those of $T_{i}$ from IRI-2007 and $T_{n}$ from NRLMSISE-00. The empirical electric field used in the GCM includes a diurnal (or UT) variation which would cause both direct heating in the polar cap region and heat transport from the auroral region to the polar cap (e.g., Fujiwara and Miyoshi, 2010); however, the empirical model does not include localized structures and does not describe localized heating which would be associated with fluctuations of the electric field. The electric field, or frictional heating, mentioned above should be one of the most important factors to understand the relations and discrepancies between the temperatures from observations and models in the polar cap region.

Since the ion and neutral temperatures result from the heating and cooling processes, we should clarify the climatology of the ion and neutral temperatures in the polar cap ionosphere/thermosphere to understand the energy budget in the region, both from observations and GCM simulations. In the future work, the ion temperatures obtained from the ESR observations will be compared with those simulated by our coupled whole atmosphere-ionosphere GCM, with which preliminary simulations (e.g., Jin et al., 2008, 2011) have been carried out.

\section{Summary}

We have investigated the ion temperature variations in the polar cap/cusp region of the thermosphere/ionosphere at about $300-\mathrm{km}$ altitude during the solar minimum and geomagnetically quiet periods. The IPY long-run data, which were obtained from the European Incoherent Scatter Svalbard radar (ESR) observations, during March 2007 and February 2008, are extremely helpful for describing the basic states (ground states) of the thermosphere and ionosphere during the solar minimum and geomagnetically quiet periods in the polar cap region.

The ion temperature obtained from the ESR observations shows spiky excursions due to enhancements of the geomagnetic activity. In addition, fluctuations with periods from several tens of minutes to 1-2 hours are found in the ion temperature variations. The periods and amplitudes (several tens to about $100 \mathrm{~K}$ ) of the fluctuations seem to be in agreement with those of the neutral temperature variations simulated by the whole atmosphere GCM. This suggests that the observed ion temperature variations would include fluctuations due to the lower atmospheric effects with amplitudes of several tens to about $100 \mathrm{~K}$ in this case. In addition, the diurnal variation of the ion temperature obtained from the ESR observations is almost in agreement with the diurnal variation of the neutral temperature simulated by the GCM.

The monthly-averaged ion temperatures for 12 months show similar local time (or UT) variations to each other; high temperatures appear at 03:00-05:00 UT (04:0006:00 LT), 11:00-13:00 UT (12:00-14:00 LT), and 22:0024:00 (23:00-01:00 LT). The ion temperatures also show significant seasonal variations. The amplitudes of the local time and seasonal variations observed are much larger than the ones predicted by the International Reference Ionosphere 2007 (IRI-2007) model. The GCM simulations show significant variations of the neutral temperature in the polar region compared with the NRLMSISE-00 empirical model. These results indicate that both the ions and neutrals would show larger variations than those described by the empirical models.

The ion temperature obtained from IRI-2007 is larger than the neutral temperature from NRLMSISE-00 by about $250 \mathrm{~K}$ over the ESR site. Since the ion temperatures obtained from the ESR observations vary with large amplitudes, the discrepancy between the ion and neutral temperatures would be larger than $250 \mathrm{~K}$ at a certain moment during a day, suggesting significant heat sources in the polar cap region even under solar minimum and geomagnetically quiet conditions. The ion and neutral temperatures, ion velocity (or electric field), and neutral wind velocity are closely related to each other. We should check the consistency between them, both for specific and statistical (empirical) results from comprehensive observations and simulations.

Acknowledgments. We thank the staff of EISCAT for operating the facilities. EISCAT is an international association supported by research organizations in China, Finland, Germany, Japan, Norway, Sweden, and the United Kingdom. This work was supported in part by Grant-in-Aid for Scientific Research C and B (20540435, 23340144, 23340149) and Scientific Research on Innovative Areas (20200047), and the Global COE program "Global Education and Research Center for Earth and Planetary Dynamics" at Tohoku University by the Ministry of Education, Science, Sports and Culture, Japan. A part of this work was also supported by the joint research programs of the Solar-Terrestrial Environment Laboratory, Nagoya University and the National Institute of Polar Research, Japan. The empirical models of NRLMSISE-00, IRI 2007, and the solar indices, are provided from NASA/NSSDC, web of NASA/GSFC, and NOAA/NGDC, respectively.

\section{References}

Bilitza, D. and B. W. Reinisch, International reference ionosphere 2007: Improvements and new parameters, Adv. Space Res., 42, 599-609, 2008. Clemmons, J. H., J. H. Hecht, D. R. Salem, and D. J. Strickland, Thermospheric density in the Earth's magnetic cusp as observed by the Streak mission, Geophys. Res. Lett., 35, L24103, doi:10.1029/2008GL035972, 2008

Codrescu, M. V., T. J. Fuller-Rowell, and J. C. Foster, On the importance of E-field variability for Joule heating in the high-latitude thermosphere, Geophys. Res. Lett., 22, 2393-2396, 1995.

Deng, Y., A. Maute, A. D. Richmond, and R. G. Roble, Impact of electric field variability on Joule heating and thermospheric temperature and density, Geophys. Res. Lett., 36, L08105, doi:10.1029/2008GL036916, 2009.

Fujiwara, H. and Y. Miyoshi, Characteristics of the large-scale traveling atmospheric disturbances during geomagnetically quiet and disturbed periods simulated by a whole atmosphere general circulation model, Geophys. Res. Lett., 33, L20108, doi:10.1029/2006GL027103, 2006.

Fujiwara, H. and Y. Miyoshi, Global structure of large-scale disturbances in the thermosphere produced by effects from the upper and lower regions: simulations by a whole atmosphere GCM, Earth Planets Space, 61, 463-470, 2009.

Fujiwara, H. and Y. Miyoshi, Morphological features and variations of temperature in the upper thermosphere simulated by a whole atmosphere GCM, Ann. Geophys., 25, 427-437, 2010.

Fujiwara, H., R. Kataoka, M. Suzuki, S. Maeda, S. Nozawa, K. Hosokawa, H. Fukunishi, N. Sato, and M. Lester, Electromagnetic energy deposition rate in the polar upper thermosphere derived from the EISCAT Svalbard radar and CUTLASS Finland radar observations, Ann. Geophys., 25, 2393-2403, 2007.

Hedin, A. E., Extension of the MSIS thermosphere model into the middle and lower atmosphere, J. Geophys. Res., 96, 1159-1172, 1991.

Innis, J. L. and M. Conde, Thermospheric vertical wind activity maps derived from Dynamics Explorer-2 WATS observations, Geophys. Res. 
Lett., 28, 3847-3850, 2001.

Jin, H., Y. Miyoshi, H. Fujiwara, and H. Shinagawa, Electrodynamics of the formation of ionospheric wavenumber-four longitudinal structure, $J$. Geophys. Res., 113, A09307, doi:10.1029/2008JA013301, 2008.

Jin, H., Y. Miyoshi, H. Fujiwara, H. Shinagawa, K. Terada, N. Terada, M. Ishii, Y. Otsuka, and A. Saito, Vertical connection from the tropospheric activities to the ionospheric longitudinal structure simulated by a new Earth's whole atmosphere-ionosphere coupled model, J. Geophys. Res., 116, A01316, doi:10.1029/2010JA015925, 2011.

Kanamitsu, M., K. Tada, T. Kudo, N. Sato, and S. Isa, Description of the JMA operational spectral model, J. Meteorol. Soc. Jpn., 61, 812-828, 1983.

Killeen, T. L., Y.-I. Won, R. J. Niciejewski, and A. G. Burns, Upper thermosphere winds and temperatures in the geomagnetic polar cap: Solar cycle, geomagnetic activity, and interplanetary magnetic field dependencies, J. Geophys. Res., 100, 21,327-21,342, 1995.

Liu, H., H. Lühr, V. Henize, and W. Köhler, Global distribution of the thermospheric total mass density derived from CHAMP, J. Geophys. Res., 110, A04301, doi:10.1029/2004JA010741, 2005.

Lühr, H., M. Rother, W. Kohler, P. Ritter, and L. Grunwaldt, Thermospheric up-welling in the cusp region: Evidence from CHAMP observations, Geophys. Res. Lett., 31, L06805, doi:10.1029/2003GL019314, 2004.

Maeda, S., S. Nozawa, M. Sugino, H. Fujiwara, and M. Suzuki, Ion and neutral temperature distributions in the E-region observed by the EISCAT Tromso and Svalbard radars, Ann. Geophys., 20, 1415-1427, 2002.

Maeda, S., Y. Ogawa, K. Hosokawa, S. Nozawa, S. Oyama, T. Tsuda, and A. Brekke, Ion heating in high-speed flow channel within the duskside cell of the polar-cap ion convection under large IMF-By condition, $J$. Geophys. Res., 114, A11307, doi:10.1029/2009JA014300, 2009.

Matsuo, T. and A. D. Richmond, Effects of high-latitude ionospheric electric field variability on global thermospheric Joule heating and mechanical energy transfer rate, J. Geophys. Res., 113, A07309,
doi:10.1029/2007JA012993, 2008.

Matsuo, T., A. D. Richmond, and K. Hensel, High-latitude ionospheric electric field variability and electric potential derived from DE-2 plasma drift measurements: Dependence on IMF and dipole tilt, J. Geophys. Res., 108, 1005, doi:10.1029/2002JA009429, 2003.

Miyahara, S., Y. Yoshida, and Y. Miyoshi, Dynamic coupling between the lower and upper atmosphere by tides and gravity waves, J. Atmos. Terr. Phys., 55, 1039-1053, 1993.

Miyoshi, Y., Numerical simulation of the 5-day and 16-day waves in the mesopause region, Earth Planets Space, 51, 763-772, 1999.

Miyoshi, Y. and H. Fujiwara, Day-to-day variations of migrating diurnal tide simulated by a GCM from the ground surface to the exobase, Geophys. Res. Lett., 30, 1789, doi:10.1029/2003GL017695, 2003.

Miyoshi, Y. and H. Fujiwara, Excitation mechanism of intraseasonal oscillation in the equatorial mesosphere and lower thermosphere, J. Geophys. Res., 111, D14108, doi:10.1029/2005JD006993, 2006.

Miyoshi, Y. and H. Fujiwara, Gravity waves in the thermosphere simulated by a general circulation model, J. Geophys. Res., 113, doi:10.1029/2007JD008874, 2008.

Moe, K. and M. M. Moe, The high-latitude thermospheric mass density anomaly: A historical review and a semi-empirical model, J. Atmos. Sol. Terr. Phys., 70, 794-802, 2008.

Picone, J. M., A. E. Hedin, D. P. Drob, and A. C. Aikin, NRLMSISE-00 empirical model of the atmosphere: Statistical comparisons and scientific issues, J. Geophys. Res., 107, 1468, doi:10.1029/2002JA009430, 2002.

Schunk, R. W. and A. F. Nagy, Ionospheres: Physics, Plasma Physics, and Chemistry, 554 pp., Cambridge University Press, Cambridge, 2000.

H. Fujiwara (e-mail: h_fujiwara@st.seikei.ac.jp), S. Nozawa, S. Maeda, Y. Ogawa, Y. Miyoshi, H. Jin, H. Shinagawa, and K. Terada 